\title{
Avaliação do PPA 2012-2015 do Governo do Estado da Bahia: Uma investigação da concepção, planejamento, gestão e indicadores dos programas'
}

Thaiz Braga ${ }^{2}$

Rodrigo Cerqueira ${ }^{3}$

1 Este artigo tem como referência os "Relatórios de Avaliação Inicial" dos 20 programas prioritários do PPA 2012-2015 e "Relatório Parcial da Avaliação de Indicadores do PPA 2012-2015" do Governo do Estado da Bahia, elaborados entre dezembro de 2012 e dezembro de 2013. Os autores agradecem a valorosa contribuiç̧ão dos servidores da Seplan: Carmen Lima, Marina Rapp, Egla Costa, Renato Carneiro; e da Universidade Corporativa do Serviço Público (UCS/Seplan), Patrícia Miranda; além dos estagiários Vitor Campos, Fábia Santos, Taiane Moreira, Manoel Ribeiro, Fábio Senna, Fabiana dos Santos e Marcele Daltro.

2 Economista, mestre em economia pela Universidade Estadual de Campinas (UNICAMP), doutora em Administração pela Universidade Federal da Bahia (UFBA), ex-Diretora de Avaliação da Superintendência de Gestão e Avaliação (SGA) da Seplan e Coordenadora de Monitoramento e Avaliação do Projeto de Desenvolvimento Rural Sustentável - Bahia Produtiva, da Companhia de Desenvolvimento e Ação Regional (CAR) da Secretaria de Desenvolvimento e Ação Regional (Sedir).

3 Economista, graduado pela Universidade Federal da Bahia (UFBA), ex-Coordenador de Avaliação da Diretoria de Avaliação (DAV) da Superintendência de Gestão e Avaliação (SGA) e Especialista em Produção de Informações Econômicas, Sociais e Geoambientais da Superintendência de Estudos Econômicos e Sociais da Bahia (SEI) da Seplan. 


\title{
Resumo
}

A Secretaria do Planejamento do Estado da Bahia vem, Desde abril de 2011, introduzindo a sua metodologia de Monitoramento e Avaliação dos Programas DE GoVERnO, E A PARTIR DE MEADOS DE 2012, ADOTOU UMA METODOLOGIA DE AVALIAÇÃO DAS AÇÕES DE POLÍTICA PÚBLICA E INDICADORES MATERIALIZADOS NO PPA 20122015. OS PROJETOS dE AVALIAÇÃO PROPOSTOS PARA O GOVERNO DO ESTADO DA BAHIA Foram uma ADAPTAÇÃo da Avaliação Executiva de Projetos e AvaliaçÃo ExeCutiVA dos INDICADORES, AMBOS dO GOVERNO dO Estado de MinAs GERAIS. O OBJETIVO DA AVALIAÇÃO FOI A INVESTIGAÇÃO DOS ELEMENTOS DE CONCEPÇÃO, PLANEJAMENTO E GESTÃO INICIAL OQUE ESTAVAM IMPACTANDO NA EXECUÇÃO DOS PROGRAMAS JÁ PUBLICADOS NO PPA, ALÉM DA OUUALIDADE DOS INDICADORES UTILIZADOS PARA O MONITORAMENTO DA POLÍTICA PÚBLICA. PARA A REALIZAÇÃO DESTA AVALIAÇÃO FOI EFETUADA UMA PESOQUISA DE CAMPO, COMBINANDO ABORDAGENS E PROCEDIMENTOS OUANTITATIVO E OUUALITATIVO, CULMINANDO NA GERAÇÃO DE PLANOS DE MELHORIAS PARA AS FRAGILIDADES IDENTIFICADAS NOS PROGRAMAS E SEUS INDICADORES. ESTA AVALIAÇÃO APONTOU ELEMENTOS IMPORTANTES OUUE TEM INFLUENCIADO NA EXECUÇÃO/ ACOMPANHAMENTO E, PORTANTO, NO DESEMPENHO DOS PROGRAMAS, OUE SERÃO OBSERVADOS PELO MONITORAMENTO EM CURSO NO ÂMBITO DA SEPLAN.

\begin{abstract}
The Department of Planning of Bahia has, since April 2011, ROLLING OUT ITS METHODOLOGY FOR MONITORING AND EVALUATION of Government Programs, AND FROM MID-2012, ADOPTED A METHODOLOGY FOR EVALUATING PUBLIC POLICY ACTIONS AND INDICATORS MATERIALIZED IN 2012-2015 PPA. THE EVALUATION PROJECTS PROPOSED FOR THE StATE GOVERNMENT OF BAHIA WERE AN ADAPTATION OF THE EXECUTIVE EVALUATION OF PROJECTS AND EXECUTIVE EVALUATION OF INDICATORS, BOtH FROM the State GoVERnMENT of Minas Gerais. The goal of the eValuation is the INVESTIGATION OF THE CONCEPTION, PLANNING AND INITIAL MANAGEMENT THAT WERE IMPACTING ON IMPLEMENTATION OF PROGRAMS ALREADY PUBLISHED IN PPA, BESIDES THE QUALITY OF THE INDICATORS USED FOR MONITORING PUBLIC POLICY. TO ACHIEVE THIS EVALUATION A FIELDWORK WAS CONDUCTED, COMBINING QUANTITATIVE AND QUALITATIVE APPROACHES AND PROCEDURES, LEADING TO THE DEVELOPMENT OF IMPROVEMENTS PLANS FOR ADDRESSING THE WEAKNESSES IDENTIFIED IN THE PROGRAMS AND THEIR INDICATORS. THIS EVALUATION IDENTIFIED IMPORTANT FACTORS THAT HAVE INFLUENCED THE IMPLEMENTATION/MONITORING AND, THEN, THE PERFORMANCE OF PROGRAMS, AND THAT WILL BE OBSERVED BY ON COURSE MONITORING APPROACH OF SEPLAN.
\end{abstract}

\section{PALAVRAS-CHAVE:}

política pública; avaliação; monitoramento.

Revista Brasileira de Monitoramento e Avaliação | Número 7 | Janeiro-Junho de 2014

Avaliação do PPA 2012-2015 do Governo do Estadoda Bahia: Uma investigação da concepção, planejamento, gestão e indicadores dos programas 


\section{Introdução}

A Instrução Normativa no $002^{4}$, de 20 de novembro de 2012, instituiu o processo de Monitoramento e Avaliação (M\&A) dos Programas de Governo do Plano Plurianual (PPA) no âmbito do Poder Executivo do Governo do Estado da Bahia e normatizou seus procedimentos. Entretanto, mesmo antes do processo de Monitoramento e Avaliação ser disciplinado na esfera da administração pública, a Superintendência de Gestão e Avaliação (SGA) iniciou uma avaliação do desenho e da operação inicial dos programas prioritários de governo. O processo de avaliação dos programas de governo é parte componente do Sistema Estadual de Planejamento e Gestão Estratégica (Sepege), configurando um dos seus subciclos, a saber: planejamento, orçamento, execução, monitoramento e avaliação ${ }^{5}$.

Neste ciclo da gestão orientado para resultados, cumpre à avaliação o papel de colaborar para melhorar o desempenho e aumentar a transparência das políticas públicas, em execução no estado por meio dos programas do PPA 2012-2015. Com este trabalho busca-se, ainda, subsidiar o planejamento e a formulação do novo PPA 2016-2019.

Desta forma, iniciada a execução dos programas governamentais constantes no PPA 2012-2015, a SGA adotou uma metodologia para avaliação que permite fornecer aos executores dos programas uma série de propostas de ajustes nos aspectos avaliados, ao mesmo tempo que estabelece referência para a elaboração de programas de governo, com foco na estruturação de métodos e instrumentos que possibilitem a correta elaboração da proposta de política pública e aferição dos resultados esperados.

Neste contexto, de posse dos resultados da Avaliação Inicial dos programas prioritários do Governo do Estado da Bahia, e diante dos diagnósticos das fragilidades do processo de construção do plano, foi iniciada a avaliação dos indicadores do PPA 2012-2015. A proposição do projeto Avaliação de Indicadores do PPA foi motivada pela constatação da Avaliação Inicial de que os indicadores publicados no plano plurianual são insuficientes e inconsistentes com o que se pretende apontar, com repercussões importantes sobre o processo de acompanhamento, monitoramento e/ou avaliação dos programas de governo. Em resumo, a investigação quanto às características dos indicadores do PPA 2012-2015, bem como a possibilidade destes aferirem os resultados dos programas, foi iniciada a partir dos instrumentos diagnósticos da Avaliação Inicial e aprofundada na Avaliação de Indicadores, cujos resultados serão apresentados neste artigo.

Este artigo está estruturado em quatro seções. Inicialmente são apresentados os procedimentos metodológicos que nortearam a Avaliação Inicial: a caracterização da amostra, os instrumentos utilizados para a coleta de dados e o processo de devolutiva dos resultados da avaliação encontram-se descritos nesta seção. Em seguida são explicitados os resultados encontrados a partir de uma análise cruzada entre as informações provenientes das ferramentas de pesquisa utilizadas: pesquisa documental, questionário, grupo focal e entrevistas coletivas. Logo depois são apon- 
tados os principais pontos fortes e fracos dos programas, relativos à sua concepção, planejamento e gestão. Como produto desta avaliação foram elaborados planos de melhoria para os programas de governo e suas respectivas propostas de ação, cujos resultados são sumariados na sequência. Os achados da Avaliação de Indicadores do PPA foram descritos na seção seguinte, nas quais são analisadas as principais fragilidades relacionadas à construção, sistematização e comunicação dos indicadores do plano. Por fim, apresentam-se as considerações finais e sugestões para o desdobramento deste estudo em avaliações posteriores.

\section{Avaliação Inicial: metodologia}

A metodologia utilizada na Avaliação Inicial de programas de governo buscou uma aproximação com a Avaliação Executiva (AEP) ${ }^{6}$ de Projetos Estruturadores do Governo do Estado de Minas Gerais, entretanto, foi idealizada com finalidades distintas. A AEP tem como ob- jetivo analisar a efetividade geral dos Projetos Estruturadores do Estado de Minas Gerais, procurando identificar o grau de maturidade em que se encontram em termos de desenho, implementação, gerenciamento e alcance de resultados, e dessa forma, evidenciar suas melhores práticas e oportunidades de melhori).7 A Avaliação Inicial, por sua vez, difere em alguns aspectos da AEP: são avaliados programas de governo já elaborados e publicados no Plano Plurianual (PPA)

A Avaliação Inicial busca proporcionar uma visão padronizada dos programas prioritários do PPA 2012-2015. É realizada a partir dos mesmos critérios para todos os programas de governo, e concentra-se na análise de aspectos de desenho e operação do programa. Não houve pretensão de chegar a conclusões sobre os resultados obtidos, nem sobre os efeitos e os impactos dos programas do PPAuma vez que no período de realizaçãoldessa avaliação estes ainda não haviam completado um ano de execução.

\section{BAHIA (2012).}

5 Conforme Freitas (2013) o ciclo do planejamento idealizado para o Sepege comporta as fases: 1) elaboração do PPA de forma participativa (devidamente baseado em um planejamento estratégico); 2) apreciação/aprovação na Assembleia Legislativa; 3) execução das políticas públicas e possíveis modificações orçamentárias; 4) Monitoramento e Avaliação das políticas implementadas; 5) Revisão e Retroalimentação (FREITAS, 2013; IPEA, 2013).

6 A AEP do Governo do Estado de Minas Gerais tem referência teórica nas iniciativas de avaliação de programas governamentais dos Estados Unidos (Program Assessment Rating Tool-PART); e América Latina (Evaluación de Programas Gobernamentales-EPG, Chile; Consistencia y Resultados-CyR, México; Evaluación Ejecutiva-EE, Colômbia). (MINAS GERAIS, 2011a).

Revista Brasileira de Monitoramento e Avaliação | Número 7 | Janeiro-Junho de 2014

Avaliação do PPA 2012-2015 do Governo do Estadoda Bahia: Uma investigação da concepção, planejamento, gestão e indicadores dos programas 
O processo de Avaliação Inicial é constituído por cinco etapas principais: planejamento, coleta de dados, análise (relatório preliminar), devolução, e finalização (relatório final). A fase de planejamento é caracterizada pela análise de informações documentadas; pela elaboração de proposta de Matriz do Marco Lógico (MML) ${ }^{8}$ para cada um dos programas avaliados; pela elaboração dos instrumentos de coleta de dados (questionário, roteiro do grupo focal, roteiro da entrevista coletiva); e pela construção da amostra dos participantes da pesquisa.

A elaboração de uma proposta para a MML voltada aos programas avaliados foi importante para a criação de um padrão de estrutura para avaliação; comparação entre os programas;mbem como permitiu: 1) a identificação dos objetivos dos programas; 2) a análise dos indicadores propostos; e 3) a verificação das condições externas que influenciariam no alcance dos objetivos propostos.

O questionário utilizado na pesquisa foi do tipo e-survey, instrumento de pesquisa disponibilizado via plataforma web e encaminhado por e-mail com instruções para ser respondido pelo próprio investigado ${ }^{9}$. Composto de 38 questões apresentadas em quatro blocos (identificação, concepção, planejamento e gestão) o questionário teve por objetivo traduzir, a partir de perguntas específicas com respostas fechadas de múltipla escolha, o conhecimento de cada respondente sobre a concepção, o desenho, o planejamento e a execução inicial dos programas de governo ${ }^{10}$. Buscou-se identificar o perfil do respondente, a clareza dos objetivos do programa, bem como a precisão da sua concepção e elabo- ração, além de investigar os elementos de planejamento e de gestão das suas ações. No que tange aos recursos metodológicos de grupo focal e entrevista coletiva, para que o registro das respostas fosse realizado adequadamente, foi necessária a preparação antecipada de roteiros de investigação ${ }^{11}$.

Com relação aos respondentes, a amostra foi elaborada pela Seplan em parceria com as secretariais executoras dos programas ${ }^{12}$. Em função da dificuldade de identificação do universo dos servidores públicos do Estado que atuavam na operacionalização das ações dos programas, a amostra foi do tipo não probabilística, de natureza intencional, definida segundo o critério de envolvimento com a formulação e a implementação do programa selecionado. Desta forma, foi estabelecido o grupo alvo da pesquisa. Os participantes das oficinas de grupo focal foram escolhidos entre os respondentes do questionário conforme perfis específicos ${ }^{13}$. Por fim, a partir das expressões dos gestores da Seplan (superintendentes, assessores, diretores, coordenadores e técnicos), o desempenho da secretaria no processo de planejamento, construção e condução da elaboração do PPA 2012-2015 e seus reflexos nos programas,foram investigados.

Após o planejamento e preparação dos instrumentos, teve início a coleta dos dados a partir da pesquisa de campo. As técnicas empregadas foram: e-survey, grupo focal e entrevista coletiva presencial. O questionário permitiu padronizar a aplicação dos mesmos critérios a diferentes programas. O recurso ao grupo focal, por sua vez, ampliou a compreensão do significado das respostas dos questionários. Dessa forma, tornou-se possível explorar não 
apenas o comportamento das variáveis presentes nos dados quantitativos e identificar as relações existentes entre elas, mas também examinar os sentidos a elas atribuídos pela fala dos atores e de suas manifestações, elucidando os pontos não esclarecidos pela análise quantitativa dos dados) ${ }^{14}$.

A coleta de informações por meio do grupo focal foi realizada após a finalização da tabulação e da análise dos dados gerados a partir do questioná- rio. Além de contribuírem para a elaboração da versão final do roteiro de discussão no grupo focal, estes resultados orientaram o moderador na estratégia de condução do grupo.

\section{A entrevista coletiva foi realizada apenas com os gestores da Seplan, em um único dia, e trouxe elementos elucidativos quanto aos procedimen- tos de planejamento, construção e condução da elaboração do PPA 2012-2015 e suas consequ- ências para a execução dos programas ${ }^{15}$.}

8 O Marco Lógico é uma metodologia utilizada para planejamento, monitoramento e avaliação dos programas, cujo principal produto é a MML. Esta matriz é composta de informações sobre as finalidades e os propósitos do programa, os resultados ou produtos do projeto - na Avaliação Inicial identificados como a ementa, as metas e os compromissos dos programas - e, por fim, as atividades ou entregas. Na MML, cada uma dessas categorias possui uma descrição ou resumo narrativo, seus respectivos indicadores, correspondentes fontes/meios de verificação e seus pressupostos, supostos ou premissas. (BAHIA, 2011; RUA, 2000).

9 Destaca-se que, na Avaliação Inicial, os processos e instrumentos diagnósticos da AEP foram customizados às necessidades do Governo do Estado da Bahia.

10 A aplicação do questionário foi precedida de um pré-teste para ajuste da linguagem, número de questões e sua ordem de apresentação, bem como o tempo de resposta.

11 Para ter acesso aos instrumentos de pesquisa de campo completos ver Manual de Avaliação Inicial (BAHIA, 2013)

12 O primeiro passo para a seleção dos respondentes do questionário foi estabelecer contato com as secretarias responsáveis pelos programas. Esta interlocução ocorreu segundo critérios específicos: 1) articulação com o comitê gestor do programa, quando este existir; 2) articulação com o chefe de gabinete da secretaria, para aqueles programas em que uma única secretaria é responsável pela sua execução; 3) articulação com os superintendentes, para aqueles programas que tenham mais de uma secretaria responsável por sua execução. Estes interlocutores foram responsáveis pela seleção e validação inicial da amostra. À Seplan coube a elaboração e a sugestão de lista preliminar de respondentes, utilizando-se das listas de presença das mesas temáticas de formulação dos programas, quando da elaboração do PPA 2012-2015, e das listas de responsáveis pelo programa apontados no Plano de Monitoramento elaborado pela SGA (BAHIA, 2013).

13 Para a composição da subamostra do grupo focal foram consideradas importantes as seguintes características: ser responsável pelos compromissos do programa; ter trânsito no âmbito político-estratégico; conhecer a execução orçamentária; ter participado da construção do PPA; e saber sobre a execução do programa (BAHIA, 2013).

14 Para mais informações ver RUA (2011a, 2011b).

15 Foram elementos para a investigação: 1) planejamento de longo prazo como norteador da construção do PPA 2012-2015; 2) planejamento da elaboração do PPA; 3) apropriação, disseminação e aplicação da nova metodologia do PPA; 4) mobilização dos atores envolvidos na elaboração do plano; 5) tratamento e consolidação das propostas oriundas da escuta social e do planejamento territorial; 6) elaboração dos programas do PPA 2012-2015; e 7) gestão, monitoramento e avaliação do PPA 2012-2015.

Revista Brasileira de Monitoramento e Avaliação | Número 7 | Janeiro-Junho de 2014

Avaliação do PPA 2012-2015 do Governo do Estadoda Bahia: Uma investigação da concepção, planejamento, gestão e indicadores dos programas 
Todo o processo da coleta de dados foi realizado em um período de seis meses para 20 programas de governo avaliados ${ }^{16}$. Foram enviados 579 convites a 521 pessoas para responder o questionário da Avaliação Inicial. Deste total, foram registradas 465 respostas de 432 servidores públicos do Estado $^{17}$, representando um aproveitamento de aproximadamente $80 \%$ dos convites enviados e cerca de $83 \%$ da amostra de servidores. Ainda dentro do grupo dos respondentes, 159 pessoas estiveram presentes e participaram das reuniões de grupo focal para aprofundamento das respostas aos questionários dos seus respectivos programas. Ademais, estiveram envolvidas nas diversas etapas da pesquisa de campo, 22 secretarias de Estado, o gabinete do governador e a Procuradoria Geral do Estado (PGE). Para a investigação da participação da Seplan na condução do PPA, compareceram 16 servidores.

Após a fase de coleta seguiu-se a análise das informações, associando as evidências das abordagens aos diversos procedimentos utilizados. A combinação dos resultados destes instrumentos empregados na pesquisa de camp, tornou possível a verificação das fragilidades e boas práticas de cada ação de política pública, apresentadas nos relatórios da Avaliação Inicial como pontos fracos e fortes dos programas. O Plano de Melhoria, resultado desta caracterização, teve como função a geração de propostas de ajustes nos aspectos avaliados dos programas.
A devolução dos resultados da Avaliação Inicial teve como principal característica a realização de dialogo entre os avaliadores e a equipe do programa que participou do processo de avaliação. Nesta fase foi realizada uma reunião para cada programa que teve como objetivos básicos apresentar os principais resultados da avaliação e elaborar proposta de ação para implementação do plano de melhoria proposto pela Seplan, com finalidade da mitigar os problemas do programa segundo ordem de priorização estabelecida pelos próprios executores. Participaram da reunião de devolução dos resultados os respondentes do questionário on-line, assim como demais atores elencados pelos órgãos/entidades envolvidos com o programa. Estiveram presentes nas reuniões de devolutiva, 350 servidores.

Foi, então, encaminhada a versão final do relatório com a inclusão das contribuições da reunião de devolução. Neste sentido, a etapa de devolução foi fundamental para a finalização do processo de Avaliação Inicial. A última etapa da Avaliação Inicial foi a divulgação dos seus resultados.

\section{Avaliação inicial: principais resultados}

Esta seção abordará os resultados da pesquisa. Inicialmente serão apresentadas as informações concernentes ao perfil dos respondentes. Em seguida, a análise cruzada entre os dados do questionário, os achados do grupo focal e as informações concernentes à entrevista coletiva. 


\title{
- GRÁFICO 1: DISTRIBUIÇÃO DOS RESPONDENTES SEGUNDO O CARGO
}

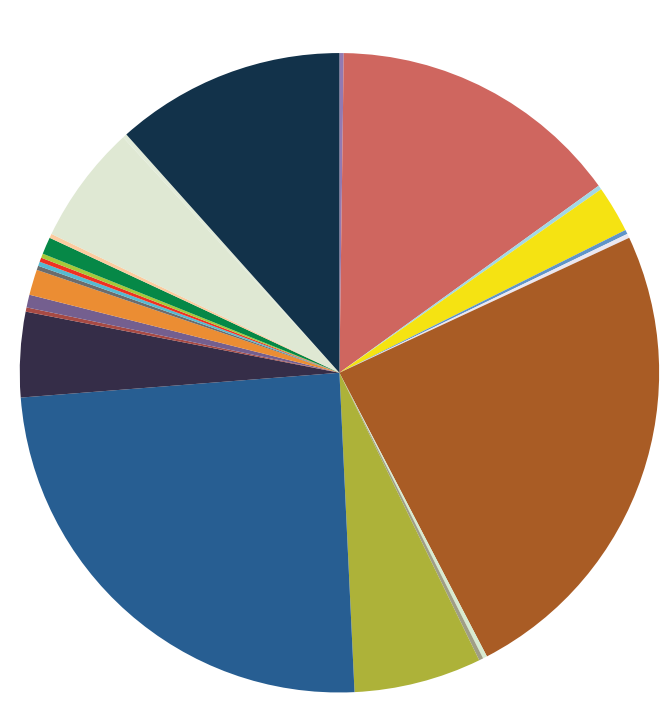

\author{
- Analista \\ - Assessor \\ Chefe de Departamente \\ Chefe de Gabinete \\ Chefe de Unidade \\ Conselheiro \\ - Coordenador \\ Coordenador Executivo \\ - Coordenador Geral \\ - Coordenador Técnico \\ - Diretor \\ Diretor Geral \\ n Diretor Regional \\ - EPPGG \\ - Gerente \\ - Líder de Projeto \\ - Procurador do Estado \\ - Secretaria \\ - Subcomandante Geral da Polícia Militar \\ - Sucordenador \\ Subsecretário \\ Superintendente \\ Supervisor estadual \\ - Técnico
}

Fonte: Dados da pesquisa dos autores

\subsection{PERFIL DOS RESPONDENTES DOS OQUESTIONÁRIOS}

Nesta primeira parteoserá apresentado o perfil dos respondentes que participaram da pesquisa de campo. A pesquisa investigou como eles estavam distribuídos, de acordo com o cargo que ocupavam. Conforme ilustrado no Gráfico 1, entre os respondentes, cerca de
87\% exerciam cargo de diretor, coordenador, assessor ou cargo de técnico.

No que diz respeito ao vínculo com o órgão executor, dos 465 respondentes, mais da metade $(59,1 \%)$ pertenciam à categoria Temporário (Comissionada, Função Gratificada, REDA), enquanto 40,9\% faziam parte do quadro efetivo (Estatuário, CLT) do Estado.

16 Os programas foram selecionados considerando os seguintes critérios: 1) serem estratégicos para a inclusão social e afirmação de direitos; 2) possuir estratégia para o desenvolvimento sustentável do Estado da Bahia; 3) registrarem elevados valores de investimentos.

17 Em alguns casos, alguns servidores do estado, em função do seu envolvimento com mais de um dos programas do PPA 2012-2015 e dada a sua importância estratégica, foram convidados a responder o questionário mais de uma vez para programas diferentes. Desta forma foi registrado um número maior de respostas aos questionários, que aquelas associadas apenas ao número de respondentes constantes do banco de dados da pesquisa eletrônica.

Revista Brasileira de Monitoramento e Avaliação | Número 7 | Janeiro-Junho de 2014

Avaliação do PPA 2012-2015 do Governo do Estadoda Bahia: Uma investigação da concepção, planejamento, gestão e indicadores dos programas 


\section{- GRÁFICO 2: DISTRIBUIÇÃO DOS RESPONDENTES SEGUNDO O TIPO DE VÍNCULO COM O ÓRGÃO/ENTIDADE}

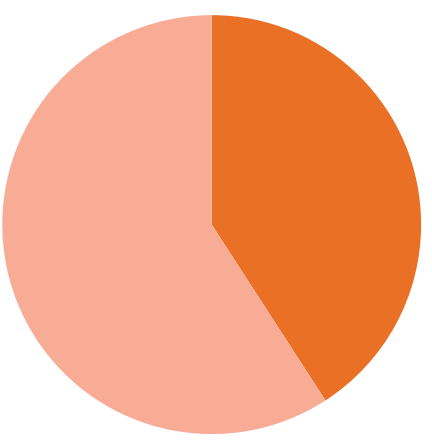

Efetivo (Estatutário, CLT)

- Temporário (Comissionado, Função

Gratificada, REDA)

Fonte: Dados da pesquisa dos autores

\section{- GRÁFICO 3: DISTRIBUIÇÃO DOS RESPONDENTES SEGUNDO A FUNÇÃO} ATUAL NO PROGRAMA DE GOVERNO

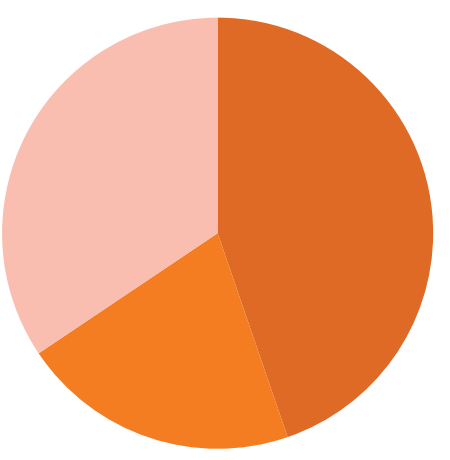

Acompanhamento

- Execução

Gestão

Fonte: Dados da pesquisa dos autores

Quanto à distribuição dos respondentes segundo a atividade que exerciam no período da pesquisa, verificou-se, conforme ilustrado no Gráfico 3, qu, do total de pesquisado,
$44,7 \%$ estavam vinculados ao programa em atividades de acompanhamento, 34,4\% em função de gestão e menos de $1 / 4$ em atividades de execução. 


\section{GRÁFICO 4: DISTRIBUIÇÃO DOS RESPONDENTES SEGUNDO A PARTICIPAÇÃO NA FORMULAÇÃO/REFORMULAÇÃO DO PROGRAMA DE GOVERNO NO PPA 2012-2015}

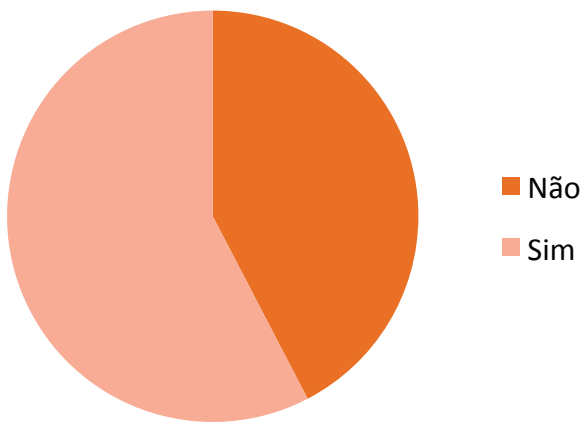

Fonte: Dados da pesquisa dos autores

O Gráfico 4 apresenta a distribuição dos respondentes de acordo com a participação na formulação/reformulação do programa durante a elaboração do PPA 2012-2015. Do total de pesquisados, 57,6\% afirmaram terem participado do processo de elaboração.

\subsection{ANÁLISE CRUZADA}

\section{DOS RESULTADOS DA MML,} QUESTIONÁRIO, GRUPO FOCAL E ENTREVISTA COLETIV

Nesta seção, serão sumariados os principais resultados sobre a concepção, o desenho, o planejamento e a execução inicial dos programas de governo priorizados. Estes resultados foram possibilitados pela triangulação de métodos e instrumentos de pesquisa.

São elementos considerados para a Avaliação Inicial dos programas e relativos à MML: 1) a identificação da finalidade/objetivo e pressupostos do programa e verificação da adequação da estrutura do programa para atingir o objetivo; 2) a análise dos indicadores propostos para verificação das ações do programa.

Quanto à pesquisa de campo, os recursos metodológicos questionário e grupo focal foram desenhados para possibilitar a avaliação das seguintes dimensões do programa: 1) concepção: existência de um diagnóstico da situação-problema; clareza do escopo, objetivo e resultados esperados do programa; precisão dos compromissos, metas e entregas; desdobramento das ações orçamentárias para o alcance do objetivo geral; 2) planejamento: utilização de ferramenta de planejamento para formulação do programa; grau de aderência em relação à estratégia de governo de médio e longo prazo e ao planejamentooestratégico do órgão/entidade responsável

Revista Brasileira de Monitoramento e Avaliação | Número 7 | Janeiro-Junho de 2014 
pelo programa; existência de mecanismos de análise de risco; suficiência dos recursos disponíveis para resolução da situação-problema, compromissos e metas; definição clara de competências; e 3) gestão, cujas dimensões estudadas foram: alinhamento entre o programa planejado e as atividades em execução; existência de instância específica de gestão para o programa; qualidade dos indicadores selecionados e publicados no PPA; mecanismos de acompanhamento e monitoramento das atividades e ações do Programa.

Por fim, as entrevistas coletivas realizadas com os gestores da Seplan destacaram o pro- cesso de elaboração do PPA 2012-2015 e forneceram pistas sobre os possíveis impactos da estruturação dos programas de governo na sua atual execução.

Entre os principais elementos elencados pela Avaliação Inicial, destacam-se as fragilidades (pontos fracos), que foram elaboradas a partir dos resultados obtidos dos instrumentos qualitativo e quantitativo e que serviram de base para a elaboração dos Planos de Melhorias dos 20 programas prioritários de governo. Estas fragilidades são apresentadas a seguir, separadas pelos seus respectivos blocos de elementos avaliados:

\section{- QUADRO 1: PONTOS FRACOS - CONCEPÇÃO}

\section{CONCEPÇÃO}

Embora a origem do programa seja atribuída aos estudos setoriais, estes não foram elaborados especificamente para a caracterização da situação-problema e planejamento do projeto de intervenção;

As sugestões da sociedade civil acolhidas pelo Plano Plurianual Participativo (PPA-P) não foram absorvidas no programa. Observaram-se dificuldades relativas ao fato do processo de elaboração do PPA e PPA-P ter se dado de forma concomitante;

Escopo do programa demasiadamente amplo, dificultando a identificação dos limites de atuação. A falta de uma proposta clara de planejamento de longo prazo para o Governo Estadual e, consequentemente, a ausência de diretrizes para as secretarias, prejudicou o estabelecimento de ementas menos "difusas" para os programas;

Inexistência de mecanismos de identificação e mapeamento dos riscos que envolvem o programa, de instrumentos para a efetiva gestão dos riscos, quando identificados, ou mesmo de um plano de ação para a sua mitigação;

O estabelecimento das prioridades por Território de Identidade (TI) não precedeu a formulação/concepção do programa. Porém, quando precedeu, houve inconsistências entre a abordagem territorial e os atributos territoriais: não foram identificadas as carcterísticas de cada município pertencente ao território, suas necessidades e/ou os impactos regionais das ações de política pública;

Não há claro desdobramento do escopo do programa em atividades executáveis, dificultando a identificação das ações e estratégias a serem adotadas para a realização do objetivo do programa;

Existência de um grande número de ações de naturezas diferentes e muitas vezes superpostas resultando em desperdício de recursos e esforços, além de retrabalho. 


\section{QUADRO 2 - PONTOS FRACOS - PLANEJAMENTO}

\section{PLANEJAMENTO}

Carência no que tange à utilização de ferramentas de planejamento necessárias à garantia de critérios mínimos de consistência do programa;

Fragilidades quanto ao fornecimento de suporte técnico e metodológico às equipes para apropriação dos instrumentos necessários à formulação/planejamento do programa, em função da dificuldade de apropriação e disseminação da metodologia e de comunicação entre a Seplan e as demais secretarias;

Baixa capacidade de resposta dos órgãos/entidades em face aos desafios colocados para a execução das ações relacionadas aos compromissos sob sua responsabilidade;

Recursos (financeiros, humanos, materiais e tecnológicos) alocados para a consecução das metas dos compromissos insuficientes;

Insegurança quanto ao prazo para cumprimento das metas estabelecidas no programa;

Alocação das equipes de trabalho segundo competências previamente definidas não foi realizada, o que resulta em desvios de função, lacunas de competências e conflito de competências institucionais;

Participação dos atores externos ao Governo Estadual na execução do programa marcada pela fragilidade dos vínculos estabelecidos. Os entraves burocráticos, bem como a falta de estrutura das entidades parceiras foram caracterizados como empecilhos relevantes para atingimento das metas do programa;

Baixa eficácia dos mecanismos de comunicação intragovernamental. Não foi percebido um fluxo contínuo de informações entre os atores relevantes do programa.

Fonte: Dados da pesquisa elaborados pelos autores

\section{OUADRO 3: PONTOS FRACOS - GESTÃO}

\begin{tabular}{|c|}
\hline GESTÃO \\
\hline Alterações entre o planejado (e publicado no PPA) e o executado; \\
\hline Baixa complementaridade e/ou interdependência dos compromissos na realização do programa; \\
\hline Ausência de instância de gestão do programa; \\
\hline $\begin{array}{l}\text { Falha na articulação entre os órgãos/entidades executores e, consequentemente, desconhecimento das ações dos órgãos/ } \\
\text { entidades participantes do programa; }\end{array}$ \\
\hline $\begin{array}{l}\text { Desconhecimento do quanto cada ação do programa colabora para a realização do objetivo deste, de forma que não há insu- } \\
\text { mo para o redirecionamento da estratégia de ação; }\end{array}$ \\
\hline $\begin{array}{l}\text { Falhas na escolha e elaboração dos indicadores, que vão desde não existir o mínimo de informações para sua utilização, como } \\
\text { fonte de dados e periodicidade, até o ponto de não representarem bem o que pretendem; }\end{array}$ \\
\hline $\begin{array}{l}\text { Dificuldade de definir indicadores de resultados para o programa. Não foram estabelecidos indicadores com as propriedades } \\
\text { desejáveis (relevância, validade, confiabilidade, abrangência, especificidade e inteligibilidade), o que resultou na inconsistên- } \\
\text { cia e na inadequação destes indicadores para o efetivo monitoramento e/ou avaliação do programa; }\end{array}$ \\
\hline
\end{tabular}

Fonte: Dados da pesquisa elaborados pelos autores

Revista Brasileira de Monitoramento e Avaliação | Número 7 | Janeiro-Junho de 2014

Avaliação do PPA 2012-2015 do Governo do Estadoda Bahia: Uma investigação da concepção, planejamento, gestão e indicadores dos programas 


\section{- OUADRO 4: RESUMO DAS PROPOSTAS DE MELHORIA PARA OS PROGRAMAS AVALIADOS}

\section{CONCEPÇÃO}

PLANEJAMENTO

GESTÃO
Implantar prática de realização de estudos diagnósticos sobre as áreas de atuação dos órgãos/entidades responsáveis pelo programa. Esta ação é fundamental para melhorar a definição do escopo das ações de política pública, de maneira que compromissos, metas, entregas, ações e limites de atuação do programa coincidam com seu objetivo e estratégia de atuação.
Identificar e analisar os pontos de inconsistência no planejamento do programa e propor os ajustes cabíveis, segundo os instrumentos disponíveis (programação orçamentária, mediante qualificação das ações das Leis Orçamentárias Anuais - LOAs).
Estabelecer uma instância de gestão específica para os programas.
Estabelecer métricas para aferição dos resultados do programa.
Oferecer capacitação para a utilização generalizada das ferramentas de análise de riscos.
Capacitar as equipes responsáveis pela comunicação das informações sobre a execução e os resultados do programa.
Elaborar proposta para a territorialização das metas dos programas, identificando os atributos dos territórios, suas necessidades ou os impactos regionais das ações de política pública. Com base nesses resultados, explicitar as prioridades segundo os territórios de identidade.
Realizar o mapeamento e a análise dos riscos das metas seguindo os seguintes passos: aquisição de instrumentos de análise de riscos, elaboração de indicadores de monitoramento e plano de ação para mitigação do risco.
Elaborar proposta de publicização qualificada e específica das ações dos programas para a sociedade, o governo e outros atores importantes.
Implantar ou fortalecer metodologias de gestão por competências das equipes de trabalho.
Constituir espaço específico para discussão e apresentação de propostas de solução para os desafios da intersetorialidade e da comunicação intragovernamental.

Introduzir a cultura do monitoramento

Capacitar as equipes responsáveis pela execução dos programas. e avaliação, com reconhecimento do papel fundamental desta etapa do programa.

Identificar e analisar as lacunas de número e de capacidades da equipe técnica dos programas e propor mecanismos para tornar a alocação de Realizar Avaliação dos Indicadores do PPA 2012-2015. pessoal mais eficiente.

Formar grupo para identificar, analisar e propor soluções para a baixa capacidade de resposta dos órgãos/ entidades responsáveis pela execução, incluindo as situações de superposição de atividades
Reelaborar os indicadores do PPA de modo a obter mais fidedignidade aos resultados pretendidos pelo programa. 


\subsection{PROPOSTAS DE MELHORIA}

Com base nas fragilidades apontadas pela MML e pela pesquisa de campo, as propostas de melhoria estão relacionadas conforme apresentado no Quadro $4^{18}$.

\section{Avaliação dos indicadores do PPA metodologia e resultados}

Os relatórios da Avaliação Inicial, elaborados pela Seplan no período de 2012 a 2013, deixam claro que, embora a utilização de indicadores no plano plurianual seja uma exigência legal, estes não foram constituídos com as propriedades desejáveis a um bom indicador (relevância, validade, confiabilidade, abrangência, especificidade e inteligibilidade). Esta fragilidade culminou na inconsistência e na inadequação dos indicadores do PPA para o efetivo monitoramento e/ou avaliação dos programas de governo.
A investigação quanto às características dos indicadores do PPA 2012-2015, foi, primeiramente, realizada a partir dos instrumentos diagnósticos da Avaliação Inicial, a saber: elaboração de proposta de Matriz do Marco Lógico (MML) e pesquisa de campo (aplicação de questionário, realização de oficinas de grupo focal, execução de entrevista coletiva).

A MML, ainda que de forma preliminar, possibilitou a investigação das fontes de verificação e demais características (abrangência geográfica, periodicidade e acessibilidade) de cada indicador do Plano. As informações provenientes dos outros instrumentos de pesquisa da Avaliação Inicial foram organizadas segundo a classificação do conteúdo das dimensões focais avaliadas (concepção, planejamento e gestão) ${ }^{19}$ e são apresentadas na sequência. No Quadro 5 são enumerados os problemas, as ações e as tarefas para a correção das fragilidades relativas à construção, sistematização e comunicação dos indicadores ${ }^{20}$.

18 Para cada um dos pontos abordados nos Planos de Melhoria foram elaboradas Propostas de Ação para implementação dos planos. Para conhecimento destas propostas ver Relatórios de Avaliação Inicial (BAHIA, 2013b).

19 As questões relativas a indicadores verificadas na elaboração da MML estão referidas à estruturação e construção dos programas e estão inseridas no bloco Concepção da Avaliação Final. Já, as informações coletadas através dos questionários, oficinas de grupo focal e entrevista coletiva tratam da capacidade dos indicadores de aferir adequadamente os resultados do programa, e são avaliadas no bloco Gestão da Al.

20 As Propostas de Ação são originárias dos "Planos de Melhoria" produto da consolidação dos resultados da Avaliação Inicial. A versão final das propostas de ação foi elaborada segundo procedimentos do Método de Análise e Solução de Problemas (MASP) (HOSKEN, 2013), em que foram identificados os problemas relacionados aos indicadores, suas causas e as tarefas para mitiga-los.

Revista Brasileira de Monitoramento e Avaliação | Número 7 | Janeiro-Junho de 2014

Avaliação do PPA 2012-2015 do Governo do Estadoda Bahia: Uma investigação da concepção, planejamento, gestão e indicadores dos programas 
QQUADRO 5: PROPOSTAS DE AÇÃO AVALIAÇÃO INICIAL - INDICADORES

\section{$\begin{array}{lll}\text { UTILIZAÇÃOO CAUSAS DO PROBLEMA } & \text { AÇÃO } & \text { TAREFA }\end{array}$}

\begin{tabular}{|l|l|l} 
& $\begin{array}{l}\text { Consolidar sistema de acom- } \\
\text { panhamento a partir das bases } \\
\text { Dificuldade de sistema- } \\
\text { tização da informação: } \\
\text { a informação não é }\end{array}$ & $\begin{array}{l}\text { de disponíveis para os } \\
\text { programas. }\end{array}$
\end{tabular}

1 - Identificar todos os registros administrativos, bem como os dados disponíveis. 2 - Consolidar, através de um sistema de banco de dados, as informações de todos os registros administrativos existentes para os programas. Fragilidade sistemas de informação.

Indicadores insuficientes, incorretos e/ou inadequados (tipo, periodicidade e abrangência)

ingor

organizada, atualizada

e disponibilizada a

Capacitar as equipes responsáveis pela execução do programa em sistematização (coleta, tratamento e atualização) e comunicação das contento.
Descontinuidade dos fluxos e falta de tempestividade das informações.
Estabelecer mecanismos

(instrumentos de coleta/ bancos de dados/meios de comunicação) que garantam a alimentação contínua de informações para os executores dos programas.
1 - Identificar os profissionais responsáveis pela sistematização da informação. 2 - Programar e oferecer cursos de capacitação para os profissionais responsáveis pela sistematização das informações e elaboração dos indicadores.

1- Implantar o Plano de Monitoramento e o Módulo de Monitoramento e Avaliação do Sistema Integrado de Planejamento, Contabilidade e Finanças do Estado da Bahia (Fiplan).

2 - Capacitar e responsabilizar todos os envolvidos na execução do programa para a correta utilização do Sistema Corporativo.

3 - Disponibilizar as informações de todos os registros administrativos existentes para o programa.

4- Estabelecer fluxo contínuo de informações entre os executores do programa.

Processo de construção dos indicadores frágil. Baixa capacidade da Secretaria de Planejamento (Seplan) e demais secretarias executoras para a elaboração dos indicadores.

Capacitar as equipes responada e especialização em M\&A. de processos, produtos, efeitos ou resultados.

Inadequação dos critérios de aferição dos resultados das ações dos programas.

Falhas na escolha e na elaboração do indicador. Estas vão desde não possuir o mínimo de informações para sua utilização, como fonte de dados e periodicidade, até o ponto de não representar bem o que se pretende. sáveis pela elaboração de indicadores do programa em elaboração de indicadores (acompanhamento, monitoramento e avaliação) das áreas correlatas.

Oferecer capacitação continu-

Elaborar indicadores de resultados/desempenho para os programas.

1 - Identificar os profissionais responsáveis pela elaboração de indicadores. 2 - Identificar as principais lacunas de capacitação dos profissionais responsáveis pela elaboração de indicadores.

3 - Programar e oferecer cursos de capacitação dos profissionais responsáveis pela elaboração dos indicadores, monitoramento e avaliação.

1 - Formar equipe técnica para estabelecer métricas para aferição de resultados e elaboração dos indicadores.

Reelaborar os Indicadores do PPA, de modo a obter mais fidedignidade aos resultados

1. Realizar Avaliação dos Indicadores do Programa no PPA 2012-2015. 
Dando seguimento a consolidação do objetivo proposto, a Avaliação de Indicadores do PPA foi realizada, a partir da análise mais aprofundada de cada um dos indicadores do $\mathrm{PPA}^{21}$.

A Avaliação dos Indicadores foi constituída por duas etapas principais: 1) Caracterização dos Indicadores do PPA 2012-2015; e 2) Elaboração da Ficha de Avaliação do Indicador. Na primeira fase, destacam-se: a análise de informações documentadas; elaboração de banco de dados das características dos indicadores. Mais especificamente, análise dos componentes utilizados na formulação dos indicadores, além da sua disponibilidade; a confecção da matriz de análise da aderência dos indicadores aos programas do PPA; e a construção do Índice de Qualidade de Aderência dos Indicadores. Nesse momento, é investigada a capacidade dos indicadores de representar ações específicas dos programas. A Etapa II da Al é caracterizada pela avaliação dos indicadores do Plano Plurianual. Para a coleta de informação, os procedimentos adotados foram: elaboração dos instrumentos de coleta de dados (questionário, roteiro de entrevistas individuais semiestruturadas); construção do cadastro dos responsáveis pelo acompanhamento dos indicadores do PPA, população investigada na pesquisa de campo; cálculo da amostra para realização das entrevistas; e elaboração das fichas de avaliação de cada um dos indicadores do PPA.

Neste artigo, entretanto, serão apresentados apenas os resultados iniciais da Etapa I - Características dos indicadores. Desta forma, foram avaliados:

A. NOMENCLATURA do indicador: análise relativa ao nome do indicador, a fórmula de cálculo e a unidade de medida.

Com base nestas informações foi possível verificar a coerência entre os elementos elencados. A nomenclatura foi classificada como correta, inconsistente ou, em alguns casos, inconclusiva. A inconsistência pode ser constatada pelo descompasso entre o nome do indicador, sua fórmula e/ou unidade de medida (incoerência entre os elementos); pela existência de fragilidade ou incongruência nas fórmulas dos indicadores (problemas na fórmula de cálculo) ou, ainda; dada a falta de detalhamento das variáveis envolvidas na fórmula de cálculo divulgada (falta de detalhamento das variáveis), o que não permitiu a verificação da sua coerência. Além destes problemas, existiram casos em que, devido ao caráter específico das informações a que os indicadores se referem, não foi possível, mediante os dados disponíveis, a verificação da coerência, ou não, dos elementos que o compõem. Nestes casos a classificação utilizada foi inconclusiva.

21 O Plano Plurianual 2012-2015 é composto por 47 programas, e o acompanhamento das ações de governo, conforme legislação específica, acontece a partir de 152 indicadores.

Revista Brasileira de Monitoramento e Avaliação | Número 7 | Janeiro-Junho de 2014 
B. A ACESSIBILIDADE da informação: verificação da disponibilidade da informação relacionada ao indicador.

A acessibilidade foi classificada segundo os níveis de facilidade de obtenção da informação: acessível, inacessível ou caso particular. Quando o indicador foi considerado inacessível os problemas se referiram a: os dados relativos ao indicador ou suas variáveis não foram encontrados na internet (indisponibilidade na rede); o banco de dados de indicadores protegidos por senha (acesso mediante senha); ou ainda, a dificuldade de verificação das variáveis que compõem o indicador (necessidade de detalhamento). Os casos particulares referem-se àquelas situações em que o acesso aos dados não pôde ser verificado na periodicidade e na abrangência publicada no PPA e/ou do Sistema Informatizado de Planejamento (Siplan), ou as informações do indicador correspondiam a um período futuro em relação à data de elaboração do relatório. É importante destacar que a caracterização da acessibilidade do indicador foi realizada mediante a busca da informação em bases de dados de ampla divulgação, notadamente a internet (instituições de pesquisa e registro de dados, órgãos do Governo do Estado da Bahia).

\subsection{ANÁLISE DA NOMENCLATURA DOS INDICADORES}

Conforme a investigação da nomenclatura, ou da coerência entre os elementos descritivos do indicador - nome, fórmula de cálculo e unidade de medida, verificou-se que 53,9\% (82) dos indicadores do PPA apresentaram alguma inconsistência entre uma ou mais informações, enquanto $44,1 \%$ (67) mostraram coesão entre seus elementos. Os demais indicadores (3) registraram inconsistência na sua composição, impossibilitando a análise de seus elementos descritivos, conforme apresentado no Gráfico 5.

\section{n GRÁFICO 5: DISTRIBUIÇÃO DOS INDICADORES DO PPA 2012-2015 SEGUNDO A CONSISTÊNCIA DA NOMENCLATURA}

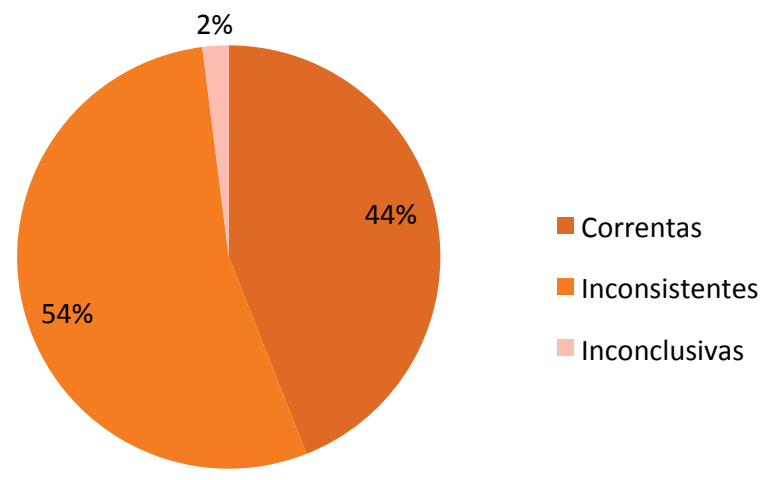


No que tange às fragilidades observadas, verifica-se que para 50 indicadores as variáveis que compõem a sua fórmula não estavam detalhadas o suficiente (falta de detalhamento das variáveis), correspondendo a $61 \%$ dos problemas relativos à nomenclatura. Para 22 indicadores o descompasso entre os elementos verificados (incoerência entre a fórmula de cálculo e/ou nome e/ou unidade de medida) foi destacado. Estes dois problemas responderam por $88 \%$ dos casos de inconsistência verificadas na nomenclatura dos indicadores do PPA 2012-2015. Para os outros dez indicadores a inconsistência refere-se a sua fórmula de cálculo (problemas na fórmula de cálculo).

Quando é realizada a análise da nomenclatura segundo a origem das fontes, verifica-se que $67 \%$ dos indicadores, que tem como fonte de referência órgãos externos à administração pública estadual, apresentaram alguma inconsistência. Infere-se deste dado a dificuldade de apropriação de indicadores de terceiros e dos elementos que os compõem por parte do Governo do estado.

\section{GRÁFICO 6: DIAGRAMA DE PARETO - NOMENCLATURA DOS INDICADORES DO PPA 2012-2015}

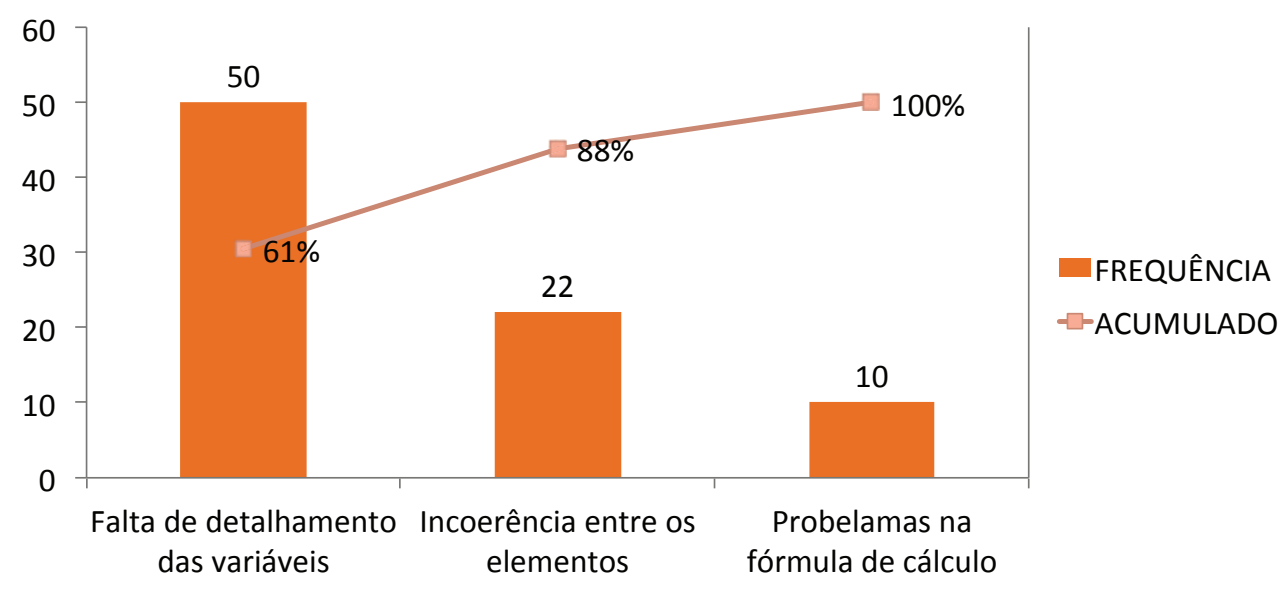

Fonte: Dados da pesquisa dos autores

Revista Brasileira de Monitoramento e Avaliação | Número 7 | Janeiro-Junho de 2014 
No exame dos indicadores produzidos por órgãos da administração pública estadual, a situação é mais equilibrada. Desta forma, 51\% dos indicadores apresentaram nomenclatura correta. A análise foi considerada inconsistente para $46 \%$ e, para 3\%, inconclusiva, conforme pode ser observado no Gráfico 7.

\subsection{ACESSIBILIDADE DOS INDICADORES}

Para a análise da acessibilidade têm-se como referências:

A. A Lei Estadual n. 12.504, de 29 de dezembro de 2011 que instituiu o PPA 2012-2015, e que em seu Artigo 90, declara que "O Poder Executivo promoverá a participação da sociedade no processo de monitoramento e avaliação dos Programas do Plano Plurianual para o quadriênio 2012-2015.", e no Artigo $11^{\circ}$ estabelece como obrigação do Po- der Executivo "[...] encaminhar [...] relatórios de avaliação parcial da execução do Plano Plurianual, [...] apresentar os resultados alcançados, comparando-os com a proposta inicial [...] além de divulgá-los na internet, em formato e linguagem acessíveis à sociedade";

B. A Lei de Acesso à Informação ${ }^{22}$ que no seu Artigo $8^{\circ}$ determina como dever dos órgãos e entidades públicas "[...] promover, independentemente de requerimentos, a divulgação em local de fácil acesso, no âmbito de suas competências, de informações de interesse coletivo ou geral por eles produzidas ou custodiadas.", e no parágrafo $1^{0}$, inciso $V$, informa que "[...] na divulgação das informações a que se refere ocaput, deverão constar, no mínimo: [...]dados gerais para o acompanhamento de programas, ações, projetos e obras de órgãos e entidades".

\section{- GRÁFICO 7: DISTRIBUIÇÃO DOS INDICADORES DO PPA 2012-2015 SEGUNDO A CONSISTÊNCIA DA NOMENCLATURA E A ORIGEM DA FONTE DE REFERÊNCIA}

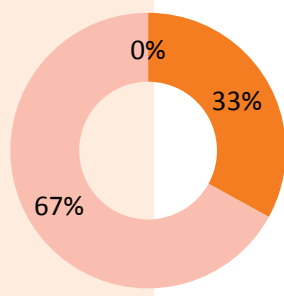

Externa

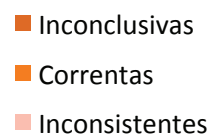

Inconsistentes

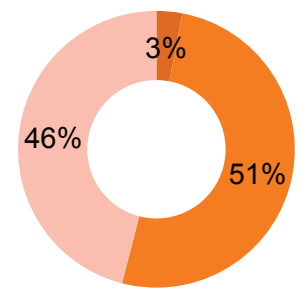

Interna
- Inconclusivas

- Correntas

- Inconsistentes 
Neste sentido a avaliação da acessibilidade dos indicadores publicados no PPA 20122015 baseou-se na verificação da disponibilidade, ou não, dos seus resultadosna internet: repositórios, banco de dados e/ou instituições de pesquisa.

Os resultados das consultas referentes à acessibilidade das informações dos indicadores do Plano Plurianual são demonstrados no Gráfico 8. Do total de 152 indicadores publicados, 37 , ou cerca de $24 \%$, permitiram acesso, seja a seus dados ou a suas variáveis, mediante consulta simples na internet, portanto, foram considerados aces- síveis. Entretanto, a maioria dos indicadores dos programas, 71\% (108 indicadores) não disponibilizaram acesso via internet a seus componentes ou resultados e foram classificados como inacessíveis. Os problemas verificados na acessibilidade destes indicadores referem-se à: indisponibilidade dos dados na rede, necessidade de senha para acesso aos bancos de dados pesquisados, ou dificuldade de verificação das variáveis que compõem o indicador (Ex. fórmula do indicadorincorreta ou não explicitada). Os outros 7 indicadores (5\%) configuram-se como casos particulares, cuja acessibilidade não pôde ser plenamente verificada.

\section{- GRÁFICO 8: DISTRIBUIÇÃO DOS INDICADORES DO PPA 2012-2015 SEGUNDO A ACESSIBILIDADE}

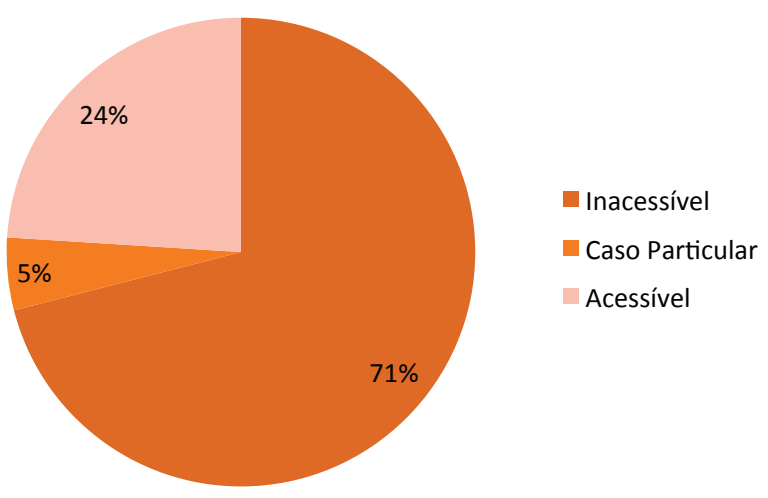

Fonte: Dados da pesquisa dos autores

Revista Brasileira de Monitoramento e Avaliação | Número 7 | Janeiro-Junho de 2014 


\section{- GRÁFICO 9: DIAGRAMA DE PARETO - ACESSIBILIDADE DOS INDICADORES DO PPA 2012-2015}

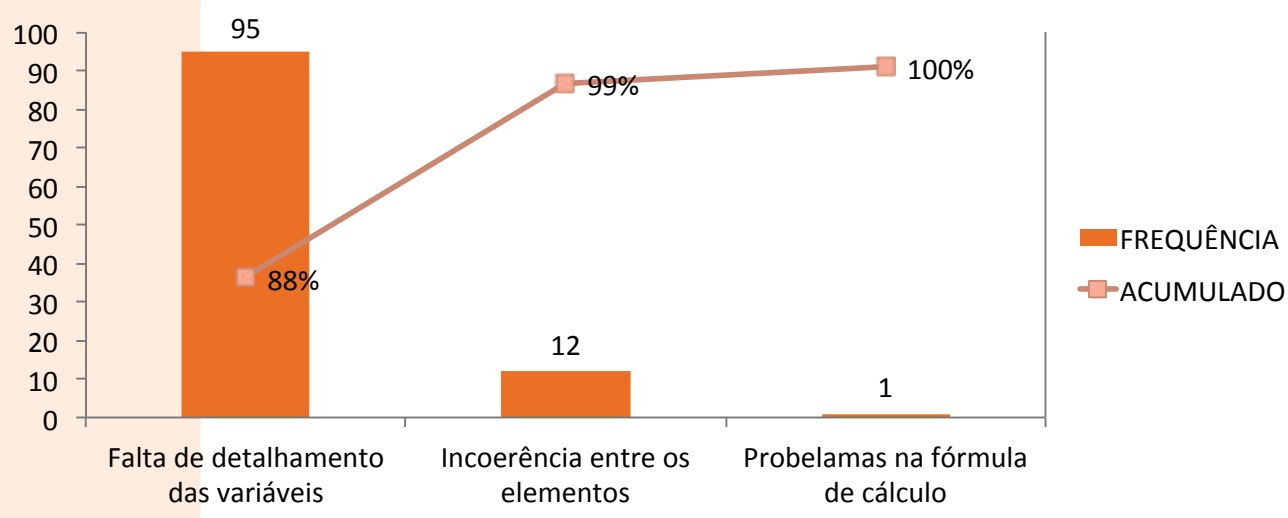

Fonte: Dados da pesquisa dos autores

As dificuldades relativas à acessibilidade aos indicadores do PPA 2012-2015 são apresentadas no diagrama de Pareto (Gráfico 9). Verifica-se que, dentre os três principais problemas de acessibilidade aos dados dos indicadores, a indisponibilidade na rede, constatada para 95 indicadores, corresponde a $88 \%$ dos problemas, seja porque estes dados não estão acessíveis nas fontes indicadas, ou ainda por estas fontes não possuírem banco de dados disponível na internet. Além da questão da indisponibilidade na rede, 12 indicadores apresentaram dificuldades de verificação dos seus dados ou variáveis, uma vez que o acesso às suas fontes exige cadastro prévio, havendo a necessidade de preenchimento de senhas. Os problemas descritos respondem por $99 \%$ das restrições à acessibilidade.

Depreende-se destes resultados preliminares a dificuldade de utilização de mecanismos de comunicação interna e externa, prejudicando sobremaneira as ações para tornar públicas as informações sobre a execução dos programas do PPA 2012-2015 e seus resultados.

Por fim, apenas um indicador não tem suas variáveis detalhadas suficientemente, de modo a permitir o acompanhamento dos seus resultados.

Ainda na análise da acessibilidade dos indicadores, quando investigada a origem das suas fontes (externa ou interna ao Governo do estado), verificou-se que $56 \%$ dos indicadores de fontes externas apresentaram seus resultados disponíveis (acessíveis) na internet, enquanto $44 \%$ estavam indisponíveis (inacessíveis). A situação é mais problemática ao se avaliar os indicadores de fontes internas. Destes, 87\% não apresentaram acessibilidade, $7 \%$ se configuraram como casos particulares e apenas $6 \%$ registraram disponibilidade dos seus dados, ilustrados pelo Gráfico 10. 


\section{n GRÁFICO 10: DISTRIBUIÇÃO DOS INDICADORES DO PPA 2012-2015 SEGUNDO A ACESSIBILIDADE E A ORIGEM DA FONTE DE REFERÊNCIA}

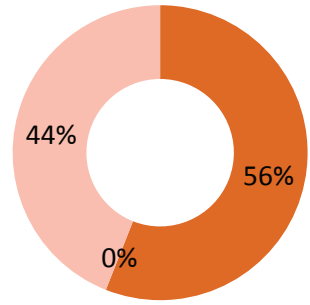

Externa

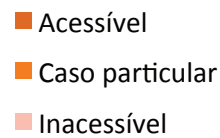

- Inacessível

Fonte: Dados da pesquisa dos autores

O cotejamento destas informações com aquelas relativas à nomenclatura dos indicadores segundo a fonte de referência dos dados (interna ou externa) deixa clara uma situação preocupante. São duas as questões principais relacionadas aos indicadores do PPA 20122015 a serem destacadas inicialmente: 1) os indicadores, em sua maioria, não estão disponíveis, principalmente aqueles oriundos de fontes internas (registros administrativos), e quando disponíveis; 2) Os indicadores não apresentam coerência interna, seja do ponto de vista da sua nomenclatura, fórmula de cálculo ou unidade de medida. Esta constatação é verificada nas fontes de dados da administração pública estadual, mas principalmente, quando analisada a proporção, para aqueles indicadores elaborados a partir de fontes externas. Embora uma parte importante do acesso ao indicador seja dada a partir de fontes externas, estas informações (nomenclatura, fórmulas ou unidade de medida) não

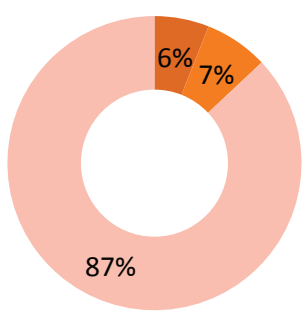

Interna
Acessível

Caso particular

- Inacessível foram corretamente coletadas, à época da elaboração do PPA.

Por fim, a Avaliação de Indicadores, ao oportunizar um diagnóstico da situação dos indicadores materializados no Plano Plurianual, permitiu verificar que a simples instituição legal da existência destes instrumentos, orientados por força normativa ao acompanhamento, monitoramento e avaliação dos programas de governo, não é garantia da usabilidade e qualidade destes.

Grande parte dos indicadores do PPA 20122015 apresentaram problemas relacionados a seus elementos descritivos e/ou não estavam disponíveis para consulta na internet. $\mathrm{A}$ análise da nomenclatura deixa claro que as informações (nome, fórmula de cálculo e unidade de medida) referentes aos indicadores, quando de fontes externas, não foram coleta-

Revista Brasileira de Monitoramento e Avaliação | Número 7 | Janeiro-Junho de 2014 
das adequadamente pelos órgãos estaduais responsáveis pela execução e/ou acompanhamento da ação de política pública. Além disto, os indicadores gerados no âmbito do próprio estado, em muitos casos, não foram elaborados ou concebidos segundo as propriedades desejáveis de um bom indicador. Em relação à acessibilidade, os indicadores escolhidos/elaborados para acompanhar, monitorar e avaliar os programas do PPA 20122015 não estavam disponíveis, conforme os preceitos constitucionais de acesso da sociedade às informações públicas, conforme Figura 1, ao lado.

Ainda na tentativa de explicitar o número de indicadores existentes no PPA 2012-2015 que atendam aos critérios estabelecidos pela Avaliação de Indicadores, verifica-se que dos 67 indicadores aprovados pela avaliação da nomenclatura apenas uma pequena parte (13) possuía disponibilidade dos seus dados na internet e, destes, uma parcela menor ainda, somente oito, estavam aptos para compor o banco de dados segundo os critérios estabelecidos, conforme se observa na Figura 2.

Considerando que não apenas os indicadores, mas também as informações necessárias para seu cômputo devem ser de fácil obtenção, a falta de acessibilidade aos indicadores do PPA, constitui um dos principais problemas a ser enfrentado pelos gestores da política pública no Governo do Estado da Bahia.

Conforme determinação legal é dever dos órgãos e entidades públicas "[...] promover, independentemente de requerimentos, a divulgação em local de fácil acesso, no âmbito de suas competências, de informações de interesse coletivo ou geral por eles produzidas ou custodiadas"23. Os indicadores devem ser disponibilizados de forma tempestiva a todos os níveis das instituições públicas e à sociedade, a partir de séries históricas que permitam comparações, e com representação regionalizada de grupos sociodemográficos. ${ }^{24}$

\section{Considerações finais}

A Avaliação Inicial de programas prioritários do Governo do Estado da Bahia teve por objetivo identificar os problemas relacionados com a concepção, o planejamento e a gestão das ações de política pública consubstanciados no PPA 2012-2015 e construir uma linha de base para as próximas avaliações, bem como contribuir, para o seu aperfeiçoamento. Este instrumento também apontou elementos importantes que podem influenciar no desempenho dos programas e, portanto, devem ser observados pelo monitoramento em curso. Por fim, esta Avaliação Inicial propõe uma série de medidas para o aperfeiçoamento do Programa, conforme apresentado no Plano de Melhoria.

Quanto a Avaliação de Indicadores, este projeto foi realizado a partir dos resultados da Avaliação Inicial, em que constatou-se a baixa capacitação na elaboração de instrumentos de coleta, sistematização, construção de bancos de dados e análise da informação, além das dificuldades de acesso às fontes de dados. Estas fragilidades repercutem sobre os sistemas de levantamento, tratamento e utilização de informações para o acompanhamento das políticas públicas e para mensuração dos resultados da ação governamental. 
FIGURA 1: SÍNTESE DA AVALIAÇÃO PARCIAL DOS INDICADORES DO PPA 2012-2015

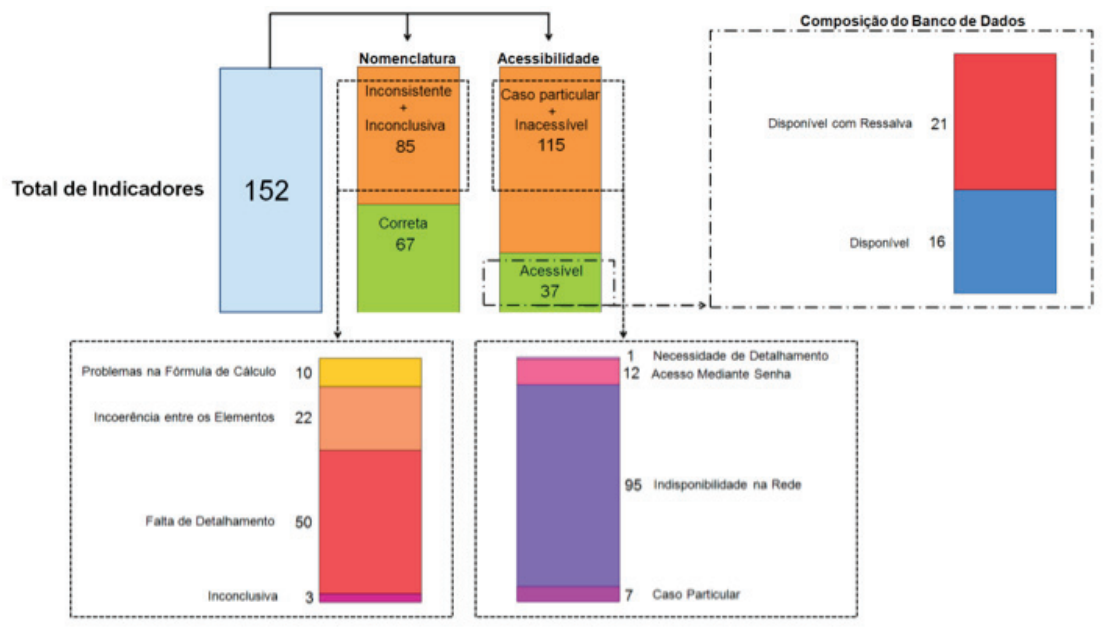

Fonte: Dados da pesquisa dos autores

FIGURA 2: AVALIAÇÃO PARCIAL DOS INDICADORES DO PPA 2012-2015, SEGUNDO OS CRITÉRIOS DE AVALIAÇÃO

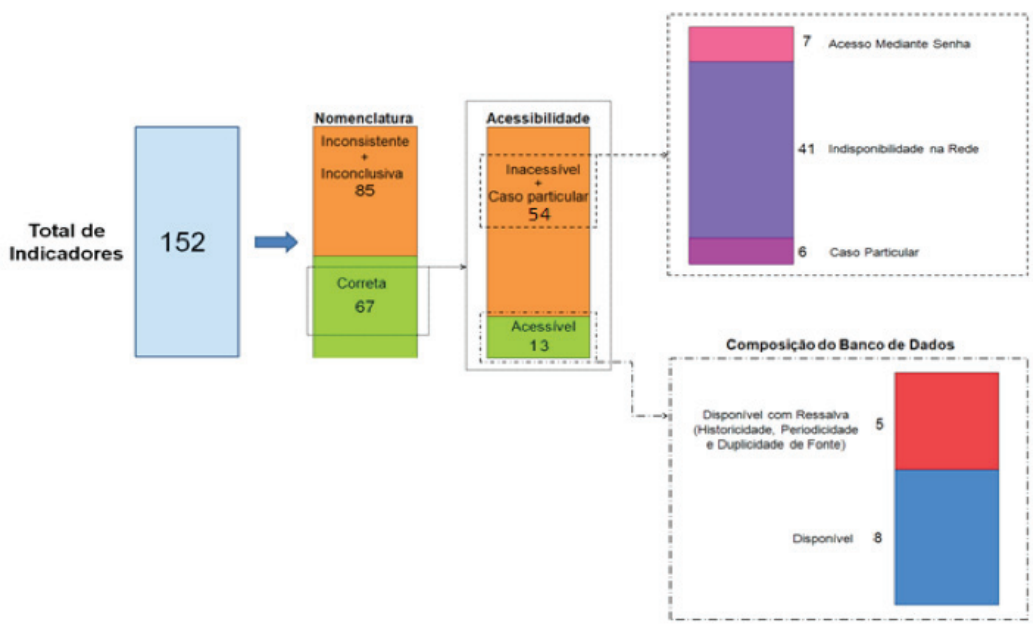

Fonte: Dados da pesquisa dos autores

23 BRASILZ (2011).

$24 \operatorname{BRASIL}(2012)$

Revista Brasileira de Monitoramento e Avaliação | Número 7 | Janeiro-Junho de 2014

Avaliação do PPA 2012-2015 do Governo do Estadoda Bahia: Uma investigação da concepção, planejamento, gestão e indicadores dos programas 
Os principais problemas relacionados aos sistemas de informações e aos indicadores foram:

1. Falhas na escolha e elaboração do indicador, que vão desde não possuir o mínimo de informações para sua utilização, como fonte de dados e periodicidade, até o ponto de não representar bem o que se pretende;

2. Dificuldade de sistematização da informação, por esta não ser organizada, atualizada e disponibilizada a contento;

3. Descontinuidade dos fluxos e falta de tempestividade das informações;

4. Baixa disponibilidade de fontes de dados/registros administrativos de informações das ações do programa;

5. Dificuldade de diferenciação entre indicadores de processos, produtos, efeitos ou resultados.

Neste sentido a avaliação dos indicadores publicados no PPA 2012-2015 justifica-se na medida em que possibilitou a verificação da capacidade destes indicadores mensurar a efetividade das políticas públicas do Governo do Estado da Bahia. Estes esforços permitirão a elaboração de um Plano Geral de Melhorias dos Indicadores do PPA 2012-2015, com sugestões que possibilitem a consolidação de um conjunto de indicadores mais eficazes e efetivos para o monitoramento dos Programas de Governo do Estado da Bahia.

Faz-se necessária, ainda, a preparação de uma avaliação de resultados, a ser realizada tão logo se verifiquem duas condições necessárias. A primeira condição refere-se a melhoria da qualidade dos indicadores e da complementação das informações relativas às metas anuais que se pretende alcançar pelo programa. A segunda condição diz respeito à forma como podem ser mais bem encadeados os elementos da matriz programática do programa, inclusive com a revisão de metas, entregas e ações orçamentárias a partir das Leis Orçamentárias Anuais (LOAs). 


\section{Referências bibliográficas}

BAHIA. Secretaria do Planejamento do Estado da Bahia. Manual de Avaliação de Programas de Governo. Salvador, 2013a.

Relatórios referentes à Avaliação Inicial de 20 programas de governo, 20 volumes. Salvador, 2013b.

Relatório Avaliação de Indicadores do PPA 2012-2015: Características dos Indicadores. Salvador, 2013c.

Instrução Normativa n. 002, de 20 de novembro de 2012. Diário Oficial do Estado da Bahia, Salvador, 20 nov. 2012.

Plano Plurianual de Gestão Governamental 2012-2015. Salvador, 2011.

BRASIL. Lei $n^{\circ} 12.527$, de 18 de novembro de 2011. Regula o acesso a informações previsto no inciso XXXIII do art. 5, no inciso II do $§ 3$. do art. 37 e no § 2 . do art. 216 da Constituição Federal; altera a Lei n. 8.112, de 11 de dezembro de 1990; revoga a Lei n. 11.111, de 5 de maio de 2005, e dispositivos da Lei n. 8.159, de 8 de janeiro de 1991; e dá outras providências. Diário Oficial [da] Republica Federativa do Brasil, Brasília, DF, 18 nov. 2011. Edição Extra, n. 221، p. 1.

BRASIL. Ministério do Planejamento, Orçamento e Gestão. Indicadores - Orientações Básicas Aplicadas à Gestão Pública. Brasília, Secretaria de Planejamento e Investimentos Estratégicos, 2012.

FREITAS, M. S. Sistema Estadual de Planejamento-SEP: Histórico, Funcionamento e o Projeto SEPEGE. Salvador, Secretaria do Planejamento do Estado da Bahia, Superintendência de Orçamento Público, jun. 2013.
HOSKEN, M. J. C. Anexo B - MASP ou Método de Análise e Solução de Problemas. In: Produzindo e montando sua qualidade. Disponível em: <http://www.qualidade.adm.br/>. Acesso em: 01 ago. 2013.

INSTITUTO DE PESOUUISA ECONÔMICA APLICADA. Planejamento e gestão governamental na esfera estadual: Uma análise comparativa dos processos, conteúdos e sistemas de acompanhamento dos PPAs. In: Relatório referente ao PPA 2012-2015 do Governo do estado da Bahia. Salvador, Secretaria do Planejamento do Estado da Bahia, 2013. (no prelo).

MINAS GERAIS. Manual da Avaliação Executiva dos Projetos Estruturadores. Governo do Estado de Minas Gerais. Belo Horizonte: Escritório de Prioridades Estratégicas, 2011a.

. Síntese dos Resultados da Avaliação Executiva de Projetos Estruturadores- 2011. Governo do Estado de Minas Gerais, Belo Horizonte: Escritório de Prioridades Estratégicas, $2011 \mathrm{~b}$.

RUA, M. G. Metodologia de monitoramento e avaliação de programas de governo. Apostila elaborada para a capacitação dos técnicos para o Programa de Monitoramento e Avaliação dos Programas de Governo do Estado da Bahia. Salvador, 2011a.

Oficina de Capacitação para Construção do Modelo de Monitoramento e Avaliação do Programa Estadual de Organizações Sociais e dos Contratos de Gestão.In: Oficinas de Monitoramento. Salvador, 2011b.

.Avaliação de Políticas, Programas e Projetos: notas introdutórias. Disponível em: <http://www.enap.gov.br/downloads/ec43ea4fUFAM-MariadasGraAvaliaPol.pdf>. Acesso em: 01 ago. 2013.

Revista Brasileira de Monitoramento e Avaliação | Número 7 | Janeiro-Junho de 2014

Avaliação do PPA 2012-2015 do Governo do Estadoda Bahia: Uma investigação da concepção, planejamento, gestão e indicadores dos programas 